\title{
THE INTRACARDIAC ELECTROGRAM AS AN AID IN CARDIAC CATHETERIZATION
}

\author{
BY \\ D. EMSLIE-SMITH
}

From the Department of Medicine, University of St. Andrews and Royal Infirmary, Dundee

Received September 14, 1954

Electrocardiograms have been recorded by unipolar leads from the great veins and cavities of the right heart during cardiac catheterization in 30 of 130 cases of congenital and rheumatic heart disease. These intracardiac electrograms have given information that has proved useful in diagnosis. Further, continuous monitoring on an oscilloscope of these tracings, rather than of records from surface leads, adds to the safety of the procedure. In this paper an attempt is made to assess the help thus afforded by intracardiac electrography.

\section{SUMmary of Relevant KNOWLEDGE of INTRACARDiaC EleCtrograms}

Studies of intracardiac electrograms obtained by cardiac catheterization were first reported by Lenègre and Maurice (1945). The normal intracardiac electrogram has been further described by Hecht (1946), Battro and Bidoggia (1947), Sodi-Pallares et al. (1947), Levine et al. (1949 $a$ and $b$ ) and Kossmann et al. (1950) and others. Relevant present knowledge, based on their work, may conveniently be summarized under three headings.

The Normal Intracardiac Electrogram. The intracardiac electrogram consists of the auriculogram and ventriculogram (Fig. 1). The auriculogram is inscribed during atrial depolarization and corresponds to $\mathbf{P}$ in surface leads; the ventriculogram is the result of ventricular depolarization and repolarization and corresponds to $Q R S$ and $T$ in surface leads.

The shape of the auriculogram bears a fairly constant relation to the position of the electrode. Fig. 2 indicates the form it takes in various chambers and great vessels of the right heart. The complex is wholly upward in the lower part, wholly downward in the upper part and diphasic in the middle part of the right atrium. The form of the ventriculogram varies much more from individual to individual and in different parts of the same heart; even in the same chamber it does not bear nearly so constant a relation to the position of the electrode as the auriculogram. Fig. 3 shows some of the common forms that are recorded from the right side of the heart.

The Electrogram from the Coronary Sinus. The coronary sinus is in close anatomical relation to the left atrium, and to the cavity and epicardium of the left ventricle. Fig 4 demonstrates how these relations affect the form of the electrogram from the coronary sinus. The left atrium is depolarized later than the right atrium: so the intrinsic deflection of the right atrial auriculogram occurs in the early part of the $\mathbf{P}$ in a simultaneously-recorded surface lead, while that from the left atrium occurs later, in the second half of $P$. Therefore the characteristic electrogram from the coronary sinus has an auriculogram of left-atrial type, while the ventriculogram borrows the $\mathbf{Q}$ from the cavity of the left auricle and reflects the late $\mathbf{R}$ and sometimes the upright $T$ of the left ventricular epicardial surface (Levine and Goodale, 1950).

Endocardial Injury Effects. Pressure of the electrode against the endocardium produces an injury current, giving S-T elevation in the ventriculogram or Sa-Ta elevation in the auriculogram. The injury current may even produce a monophasic deflection of considerable amplitude. Hellerstein and Katz (1948) studied in dogs the effects on the electrogram of endocardial pressure sufficient to produce S-T elevation. Following pressure for five seconds a normal complex appeared after a single beat; but if the pressure lasted four minutes, 




FIG. 1.-The intracardiac electrogram. The auriculogram (A) is caused by atrial depolarization, the ventriculogram (V) by ventricular depolarization and repolarization.

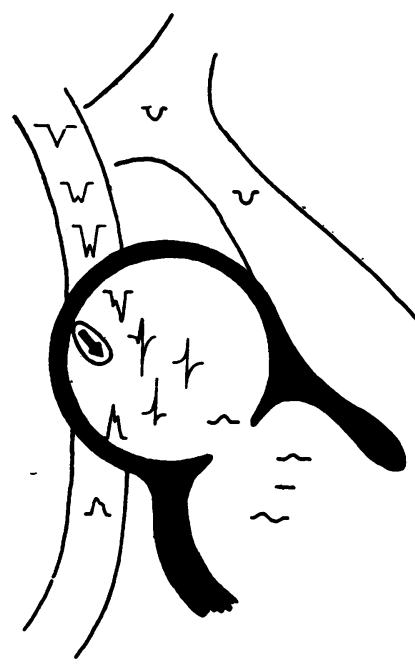

ACCESSION AURICULOGRAM

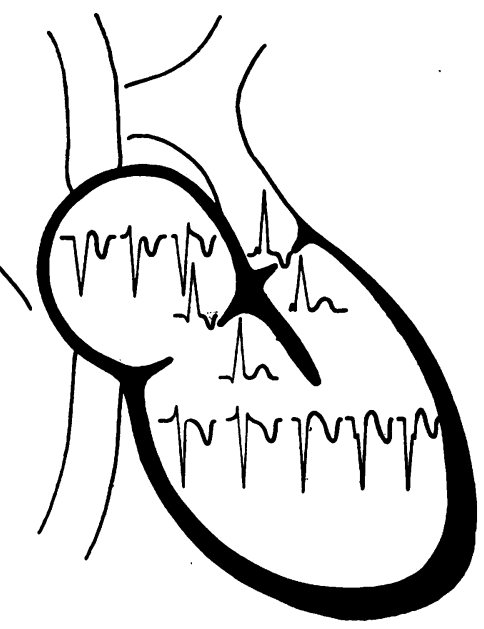

VENTRICULOGRAM



CORONARY SINUUS
FIG. 2.-Schema, showing typical auriculogram complexes as they occur in right atrium and ventricle, venæ cavæ, and pulmonary artery. Arrow shows position of sinus node.
FIG. 3.-Schema of right side of heart, showing various forms commonly adopted by the ventriculogram. Ventriculograms with a high, late $\mathbf{R}$ are sometimes found on either side of the tricuspid and pulmonary valves.
FIG. 4.-Schema of posterior aspect of heart, showing anatomical relation of coronary sinus to left atrium and to epicardium and cavity (through "window") of left ventricle. The intrinsic deflection of the auriculogram from the right atrium occurs early in $P$ in a simultaneous surface lead; that from the left atrium occurs late in $\mathbf{P}$.

S-T did not return to normal for over 20 minutes. This S-T elevation, although conspicuous in the intracardiac electrogram, is not seen in simultaneously-recorded præcordial leads (Levine et al., $1949 \mathrm{~b}$ ) or even in direct leads from the epicardium (Borchardt et al., 1948).

Intracardiac electrography has been used to investigate various fundamental electrocardiographic problems, but the only direct clinical applications that have hitherto been suggested are its use in analysing complex arrhythmias (Ferrer et al., 1949; Steinberg et al., 1952) and as a help in positioning the catheter tip at different points within the coronary venous system (Goodale et al., 1949). 
METHOD

The exploring electrode consists of an inlaid band of nickel-silver a few millimetres from the tip of a single-lumen Cournand cardiac catheter. This is connected to a terminal at the proximal end by a wire in the wall of the catheter, so that the lumen remains wholly patent. Catheters of this type are used in sizes 5 to 9, French gauge (United States Catheter and Instrument Corp.). The proximal terminal is connected by a unipolar system of Wilson type, to one channel of a three-channel Triplex electrocardiograph (Elmqvist). The other two unipolar leads are placed on the surface of the body, usually at positions VR and V1. Simultaneous permanent recordings are made from unipolar surface and intracavity leads by an optical system on photosensitive paper, and the intracardiac electrogram is also observed continuously on a Cossor doublebeam oscilloscope. By means of a capacitance electromanometer (Southern Instruments, Limited) simultaneous pressure-pulse tracings can be recorded on the fourth channel of the Triplex machine and monitored on the second channel of the oscilloscope.

\section{Personal ObSERVATIONS}

Location of the Catheter Tip. Location of the catheter tip within the heart is possible from observation of the intracardiac electrogram. For example, in Fig. 5, the catheter tip lies in the right atrium. Its movement from a low to a high position in the atrium is recorded by the electrogram, the auriculogram being at first upright, then diphasic, then wholly downward. The tracing in Fig. 6 was recorded as the catheter tip was being withdrawn from the pulmonary artery to the right

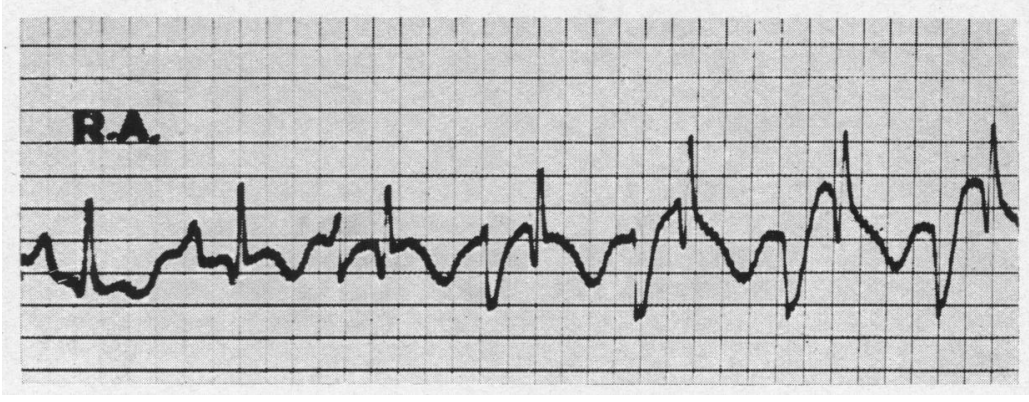

FIG. 5.-Catheter in right atrium. Wholly upright auriculogram in first two electrograms denotes electrode position low in atrium; diphasic auriculogram in third complex denotes mid-atrial position; subsequent downward auriculograms denote electrode high in atrium.

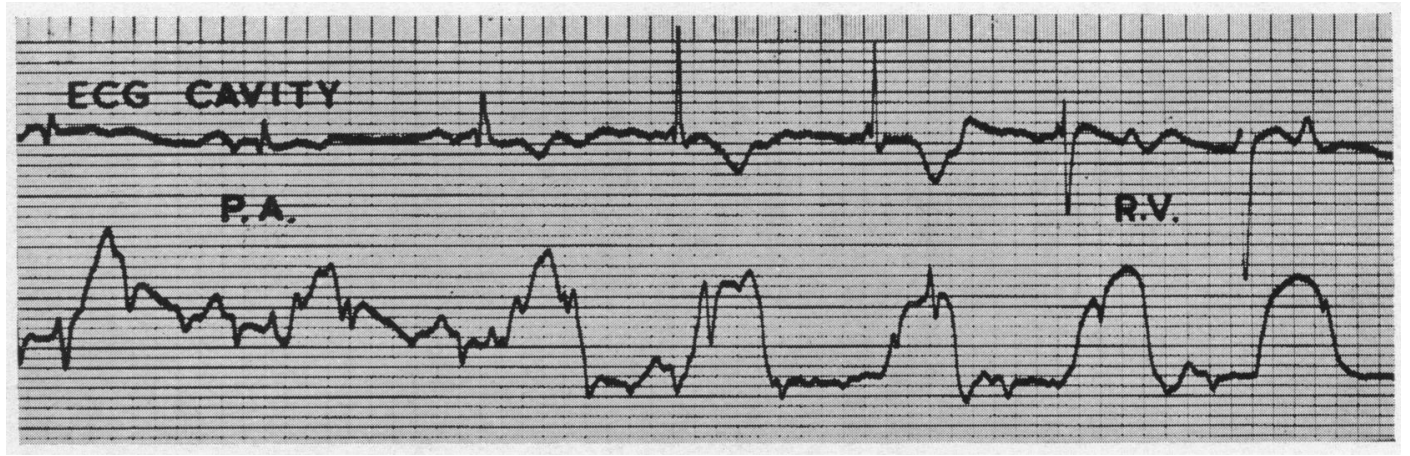

FIG. 6.-Catheter withdrawn from pulmonary artery to right ventricle. Intracardiac electrogram (above) and undamped pressure tracing (below) show change of electrode position. First three ventriculograms from infundibulum show $\mathrm{rsR}^{\prime}$ pattern; last ventriculogram (rS) is commonest pattern from right ventricular cavity. 
ventricle. The change in position is shown not only by the altered pressure pulse, but also by characteristic alterations in the ventriculogram. In Fig. 7 the fact that the intrinsic deflection of the auriculogram occurs in the second half of the $P$ in a simultaneous surface-lead electrocardiogram suggests that the arterialized blood withdrawn at this point was from the left atrium or nearby pulmonary vein. The left-ventricular cavity pattern of the ventriculogram, with $Q$ as the sole initial deflection, confirms that the sample was, in fact, from the left atrium.

When the catheter tip lies in the coronary sinus the characteristic pattern of the coronary sinus electrogram, as described above, is seen (Fig. 8). The late intrinsic deflection of the auriculogram cannot always be identified with certainty on the oscilloscope, but the ventriculogram may be diagnostic.

Fig. 9 shows a tracing made during the cardiac catheterization of a cyanosed patient thought to have a pseudotruncus arteriosus. The catheter passed from the right atrium into a high-pressure chamber which might have been a single ventricle. The ventriculogram, however, showed an $\mathbf{R}$ preceding S, as in the normal right-ventricular ventriculogram. This $\mathrm{R}$, due to depolarization of the inter-ventricular septum from left to right, argued that a septum was present. This was later proved by angiocardiography.

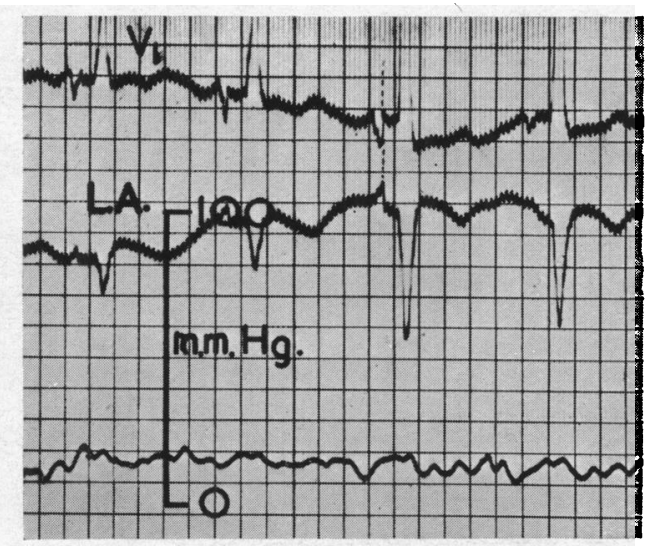

Fig. 7.-Catheter tip in left atrium (entered through atrial septal defect). Above downwards: electrocardiogram lead V1, intracardiac electrogram, pressure. The intrinsic deflection of the auriculogram occurs late in $\mathbf{P}$ in lead V1. The ventriculogram is of left-ventricular-cavity pattern $(\mathbf{Q})$.

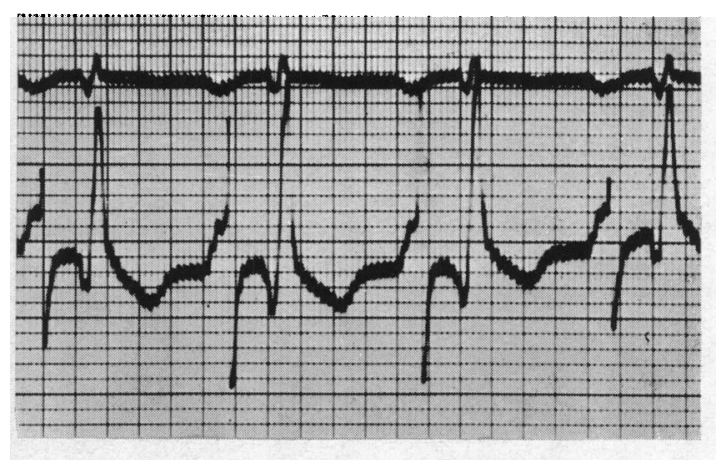

FIG. 8.-Catheter tip in coronary sinus. Electrocardiogram, lead VR above, intracardiac electrogram below. The intrinsic deflection of the auriculogram occurs late in the $P$ in lead VR. The ventriculogram reflects the $Q$ of the left ventricular cavity and the high late $\mathbf{R}$ of the left ventricular-epicardial surface.

Indication of Injury. Fig. 10 shows a tracing recorded while the catheter tip was in contact with the right ventricular endocardium. The injury current thus produced caused progressive elevation of S-T in the ventriculogram, until, after a right ventricular ectopic beat, a normal ventriculogram recurred; possibly the ectopic beat dislodged the catheter tip from the endocardium. Such S-T elevations as these may be $5 \mathrm{mV}$. or more in amplitude. We have recorded similar elevations of the $\mathrm{Sa}-\mathrm{Ta}$ segment of the auriculogram, arising from pressure of the catheter against the atrial endocardium.

\section{Discussion}

In order to reduce the risk attached to cardiac catheterization it is usual for one member of the team to watch the electrocardiogram throughout the procedure. There are certain advantages in watching the intracardiac electrogram rather than surface-lead tracings. 




Fig. 9.- Tracings from chamber wrongly postulated as single ventricle. Above downwards: electrocardiogram, lead V1, intracardiac electrogram, pressure. $\mathbf{R}$ in intracardiac electrogram means presence of interventricular septum.



FIG. 10.-Catheter tip pressing against right ventricular endocardium. Injury current causes progressive elevation of S-T in intracardiac electrogram but not in lead V1 or VR. After right ventricular ectopic beat normal ventriculograms recur.

From the point of view of both patient and operator it is important to reduce the screening time to a minimum. It is therefore helpful, particularly during withdrawal, to be able to locate the catheter tip by watching the intracardiac electrogram.

Although deliberate catheterization of the coronary sinus may be a relatively safe procedure, accidental entry occurs in some 16 per cent of cardiac catheterizations (Culbertson et al., 1949) and may not be recognized: in these circumstances it is dangerous. McMichael and Mounsey (1951) reported five cases of preæcordial distress and collapse from accidental catheterization of the coronary sinus; in one patient the coronary sinus was perforated. They stressed the difficulty of recognizing by screening in the supine position that the catheter was in the coronary sinus and not in the right ventricle, and they suggested turning the patient into the left anterior oblique position. This, however, is inconvenient, as the catheter is usually in the left arm. Moreover, Goodwin (1953) has suggested that movement of the patient with the catheter in the heart is dangerous. Goodale and Levine (1949), having deliberately catheterized the coronary sinus by screening in two planes, used the intracardiac electrogram to locate the catheter tip more precisely within the coronary venous system. The present study has shown that routine monitoring of the intracardiac electrogram readily 
shows that the catheter tip has entered the coronary sinus, and that it thus helps to prevent dangers that attend unrecognized coronary sinus catheterization.

Although endocardial trauma seems to occur much less frequently in man than in experimental animals, Goodwin (1953) reported a case in which damage to the right ventricular endocardium during an apparently uneventful catheterization led to the patient's death. As a precaution against this kind of accident the oscilloscope should be watched throughout the catheterization for the appearance of changes in the electrogram due to injury currents. The S-T elevation in the ventriculogram is readily recognized in the oscilloscopic tracing, and easily differentiated from, say, ectopic beats. Its appearance is regarded as an imperative indication for withdrawal of the catheter, since, although it appears with the slightest pressure of the electrode, it represents possible endocardial damage. This is particularly important during blood sampling when the catheter tip may lie within the right ventricle for a minute or more.

In addition to the help thus given at the time of catheterization intracardiac electrography can also assist the later analysis of tracings. The shape of the electrogram will often permanently identify the site of a pressure pulse or a blood sample. Injury currents provide a means of recognizing that unexpectedly low pressure pulses are the result of partial occlusion of the catheter by endocardium, and are consequently invalid.

The technique of intracardiac electrography described here is a simple addition to routine cardiac catheterization; it is neither expensive nor time-consuming. This preliminary report is based on a modest series of cases investigated by its aid, but it is felt that the help which it gives warrants its consideration for further and wider trial.

\section{SUMMARY}

Studies of the human intracardiac electrogram have been made during cardiac catheterization.

The normal electrogram in the right atrium and ventricle and in the coronary sinus is described, together with the effects of endocardial pressure by the catheter.

The use of intracardiac electrograms rather than surface-lead electrocardiograms lessens the risk of cardiac catheterization by reducing screening time, and helps to prevent both trauma to the endocardium and accidental catheterization of the coronary sinus. It helps the later interpretation of pressure tracings by graphically locating their site of origin and by indicating the cause of certain common distortions.

The technique described is simple, and neither expensive nor time-consuming. It deserves a wider trial.

I am very grateful to Professor I. G. W. Hill for clinical and laboratory facilities, and for his help in the preparation of the manuscript, and I acknowledge the assistance and facilities given by the technical and secretarial staff of the Department of Medicine, the nursing staff of the Professorial Unit and the staff of the Radiological Department, Dundee Royal Infirmary.

\section{REFERENCES}

Battro, A., and Bidoggia, H. (1947). Amer. Heart J., 33, 604.

Borchardt, P. R., Groedel, F. M., Kirsch, B. (1947). Exper. Med. Surg., 5, 437.

Culbertson, J. W., Halperin, M. H., Wilkins, R. W. (1949). Amer. Heart J., 37, 942.

Ferrer, M. I., Harvey, R. M., Weiner, H. M., Cathcart, R. T., Cournand, A. (1949). Amer. J. Med., 6, 725.

Goodale, W. T., Levine, H. D., Bing, R. J., Hackel, D. B. (1949). Amer. J. Med., 7, 412.

Goodwin, J. F. (1953). Brit. Heart J., 15, 330.

Hecht, H. H. (1946). Amer. Heart J., 32, 39.

Hellerstein, H. K., and Katz, L. N. (1948). Amer. Heart J., 36, 184.

Kossmann, C. E., Berger, A. R., Rader, B., Brumlik, J., Briller, S. A., Donnelly, J. H. (1950). Circulation, $2,10$.

Lenègre, J., and Maurice, P. (1945). Arch. Mal. Coeur, 38, 298.

Levine, H. D., and Goodale, W. T. (1950). Circulation, 2, 48.

—, Hellems, H. K., Dexter, L., Tucker, A. S. (1949b). Amer. Heart J., 37, 64.

- - Wittenborg, M. H., Dexter, L. (1949a). Amer. Heart J., 37, 46.

McMichael, J., and Mounsey, J. P. D. (1951). Brit. Heart J., 13, 397.

Sodi-Pallares, D. Vizcaino, M., Soberon, J., Cabrera, A. (1947). Amer. Heart J., 33, 819.

Steinberg, M. F., Kroop, I. G., Grishman, A. (1952). J. Mt. Sinai Hosp., 18, 337. 